\title{
Reducing human-elephant conflict: do chillies help deter elephants from entering crop fields?
}

\author{
SIMON HEDGES and DONNYGUNARYADI
}

\begin{abstract}
Crop raiding by elephants is the most prevalent form of human-elephant conflict and can result in devastating economic losses for farmers, loss of human lives and the killing or capture of elephants. Chilli (capsaicin)-based elephant deterrents have been promoted as tools for reducing such conflict but have been little tested. From October 2005 to April 2006 we tested crop-guarding systems around Way Kambas National Park in Indonesia. We evaluated the effectiveness of community-based guarding using traditional tools (e.g. noise-makers) at one site and community-based guarding plus chilli-grease-covered fences and tripwiretriggered sirens at another site. We monitored humanelephant conflict rates around the Park to assess the effectiveness of our mitigation trials. Over the trial period there were 34 attempts by elephants to enter crop fields at the chilli and sirens site and 57 attempts to enter fields at the conventional site but $91.2 \%$ of attempts were repelled successfully at both sites. Over the same period there were 401 crop-raiding incidents elsewhere around the Park. In 2007 farmers at both our former sites voluntarily adopted the methods that had been used at the conventional site, but not at the chilli and sirens site, and were able to repel 156 of 178 (87.6\%) attempted elephant raids. We conclude that community-based guarding using conventional tools is the key to keeping elephants out of crops and that chilli-grease fences (and sirens) do not add any significant deterrent effect but do add expense and create additional work. However, other chilli-based deterrents may be effective and chillies have value as elephant-resistant cash crops.
\end{abstract}

Keywords Crop raiding, Elephas maximus, human-wildlife conflict, Indonesia, Loxodonta africana, Sumatra, sustainable agriculture

\section{Introduction}

Crop raiding by elephants (Elephas maximus and Loxodonta africana) is the most prevalent form of human-elephant conflict and can result in devastating economic losses for farmers, loss of human lives and the

\footnotetext{
Simon Hedges (Corresponding author) International Programs, Wildlife Conservation Society, 2300 Southern Boulevard, Bronx, NY 10460, USA. E-mail shedges@wcs.org

Donny Gunaryadi Indonesia Program, Wildlife Conservation Society, Bogor, Indonesia.

Received 9 May 2008. Revision requested 23 July 2008.

Accepted 17 September 2008.
}

killing or capture of elephants in retaliation for these losses. The development of methods to reduce crop depredation by African and Asian elephants is therefore a high priority for the conservation of these species (Hoare, 1995, 2000; Kangwana, 1995; Barnes, 1996; Naughton et al., 1999; Kemf \& Santiapillai, 2000).

Human-elephant conflict is a particularly pressing problem on the Indonesian island of Sumatra (Santiapillai \& Jackson, 1990). Asian elephants E. maximus were once widespread throughout Sumatra's Lampung Province but are now restricted to just three areas: Bukit Barisan Selatan and Way Kambas National Parks and the Gunung Rindingan-Way Waya protected forest complex. Humanelephant conflict is thought to have been a major reason for the loss of nine other elephant populations in Lampung since the mid 1980s (Hedges et al., 2005). Only two of the remaining three populations, those in Way Kambas and Bukit Barisan Selatan National Parks, are large enough to be of international significance; the third is too small to be viable. Furthermore, the elephant populations in Way Kambas and Bukit Barisan Selatan National Parks remain under threat as a result of habitat loss (especially encroachment by agriculture), poaching and conflict with the people living adjacent to the Parks. Crop raiding by elephants is common and farmers sometimes retaliate by killing the animals or by encouraging the authorities to remove socalled problem elephants from the wild (Hedges et al., 2005, 2006). Crop depredation by elephants is also a major source of economic hardship for rural farmers in Lampung and this helps drive negative attitudes towards protected areas (Nyhus et al., 2000; Reilly, 2002; Sitompul, 2004; Hedges et al., 2005). Effective mitigation of human-elephant conflict around these National Parks is therefore an essential part of efforts to conserve elephants in Sumatra.

Chilli-based deterrents have been promoted as tools for reducing human-elephant conflict. Suggested uses have included hand-held pepper sprays (aerosols) or smoke canister bombs fired from simple mortar-like launchers (Osborn \& Rasmussen, 1995; Osborn, 2002; Osborn \& Parker, 2002b; WWF, 2005), pepper grease (chilli-grease), which is applied to rope fences around crop fields (Osborn \& Parker, 2002b; Parker et al., 2007), and pepper dung (chilli-dung), which is burnt to produce a noxious smoke (Osborn \& Parker, 2002a,b; WWF, 2005; Parker et al., 2007). Such uses of chillies have been reported frequently in both print and the radio/television media (Loudon, 2007; Upadhye, 2007). There have, however, been few tests of the effectiveness of chilli-based deterrents. We therefore tested 
chilli-based methods as part of our efforts to develop efficient crop-guarding systems at human-elephant conflict hotspots around the perimeter of Way Kambas National Park. Specifically, we tested conventional human-elephant conflict reduction tools and novel chilli-based elephant deterrents (chilli-grease and chilli-dung). We report here on the results of those trials.

\section{Study area}

The study was conducted in and around Way Kambas National Park in Lampung Province, Sumatra, Indonesia (Fig. 1). The Park covers $1,235 \mathrm{~km}^{2}$, all below $50 \mathrm{~m}$ altitude. As a result of commercial logging activities in the 1960 and 1970 s and frequent fires, much of the Park is covered by early-successional vegetation types (grassland and scrub). The park is in agroclimate zone $\mathrm{C}$, has a mean annual rainfall of c. 2,000 $\mathrm{mm}$ and has a single pronounced dry season of 2-6 months (March-September); dry months are those with $<100 \mathrm{~mm}$ of rainfall (Oldeman et al., 1979; UNDP/FAO, 1979). The total length of the Park's boundary is c. $227 \mathrm{~km}$ and 34 villages lie along a $148-\mathrm{km}$ sector of the Park's inland boundary. A survey in 2002 estimated a population of 180 (95\% confidence interval 144-225) elephants in the Park (Hedges et al., 2005). In addition to its importance for Asian elephants the Park contains significant populations of Sumatran rhinoceros Dicerorhinus sumatrensis and tiger Panthera tigris (Foose \& van Strien, 1997; Franklin et al., 1999).

\section{Methods}

\section{Selection of test sites}

In September 2005 we selected a previously identified humanelephant conflict hotspot on the border of Way Kambas National Park for a test of community-based crop guarding with conventional tools at one site (the conventional site) and community-based crop guarding with chilli-based deterrents and tripwire-triggered sirens at an adjacent site (the chilli and sirens site). The sites were at Labuhan Ratu 6 and Labuhan Ratu 7 (Figs 1 \& 2). Allocation of the sites to either the chilli and sirens method or the conventional method was done by flipping a coin. The conventional site covered 182.1 ha and contained three crop types: cassava (173.5 ha), rice (7.5 ha) and maize (1.1 ha). The chilli and sirens site covered 93.6 ha and contained two crop types: cassava (90.6 ha) and rice (3.0 ha). All three crop types are known to be consumed by elephants around the Park (Sitompul, 2004; Hedges et al., 2005). The difference in area between the two sites was because of the greater width of the conventional site. However, the area of the sites is irrelevant; what is important is the length of the agriculture-elephant habitat interface (which was $2 \mathrm{~km}$ at both sites; Table 1, Fig. 2) because we used attempts by elephants to cross the agricultureelephant habitat interface as our response variable (not the number of raids per site).

\section{Crop protection methods used}

Village meetings were held to explain the rationale behind the tests and to encourage local participation, and the field trials began on 22 October 2005 following a 3-week preparation period. The field trials continued until 5 April 2006; guarding occurred on 140 nights of this 165-night period, with no differences between the two sites (i.e. at both sites guarding occurred on the same nights and was maintained from before dusk to after dawn). The period of the trials coincided with the main period of crop growing in these villages.

At the conventional site the crop defences consisted of a series of eight watch-towers, each manned by 2-3 guards per night. The watch-towers were generally built close to regular elephant entry-exit points (known as active routes). The guards were equipped with spotlights and some of them had two-way radios. In addition, they also had traditional acetylene-filled bamboo tube noise-makers, which were exploded to make loud noises to scare any approaching elephants. When elephants approached the test site the guards actively chased the elephants away from the fields and back into the Park. Barbed wire and rope fences were strung across active routes and these fences had tin-can-and-stones noise-makers attached to alert the guards when elephants tried to pass the fences. Kerosene lamps were also placed at active routes as experience had shown these lamps to have a deterrent effect. The majority of the spotlights and radios were provided by our project. We also provided some of the materials necessary to build the watch-towers and assisted in their construction.

At the chilli and sirens site the methods and tools were effectively the same as at the conventional site but there were no tin-can-and-stones noise-makers, which were replaced with tripwire fences that triggered electronic sirens. Dried hot chilli powder mixed with old engine grease (chilli-grease) was also applied to rope fences and to cloth spacers attached to these fences, as well as to barbed wire fences running parallel to the cloth fences. The chilligrease was made using the hottest chillies available in Lampung Province known as Cabe Rawit or Rawit Lampung; these small green chillies were found to have the second highest capsaicin content ( $0.89 \%$ of dry weight) and to be the second most pungent of the 16 varieties of Indonesian chillies tested by Dyah Juliana et al. (1997). The most pungent was a variety found in Kalimantan (Indonesian Borneo) and so not readily available in Lampung. The organoleptic heat unit for the Rawit Lampung was tested by Dyah Juliana et al. (1997) using the Scoville method and was found to be 170,000 Scoville heat units. 


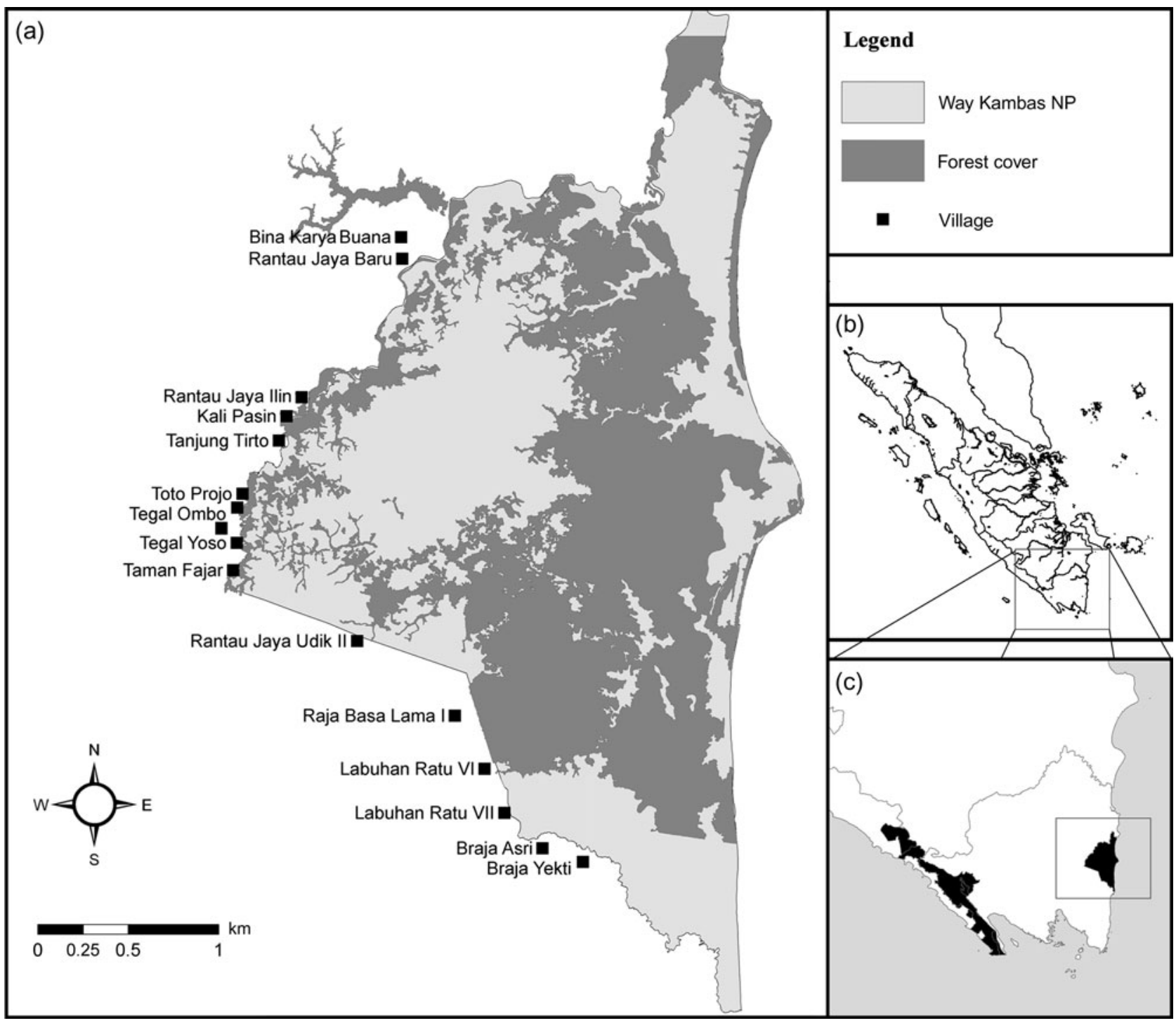

FIG. 1 (a) Way Kambas National Park (NP) on Sumatra, Indonesia, showing the remaining forest cover and the human settlements around the Park. (b) The island of Sumatra in relation to Peninsular Malaysia; the rectangle indicates the area depicted in greater detail in (c). (c) The Bukit Barisan Selatan and Way Kambas National Parks to the west and east, respectively.

A ratio of one part chilli powder to one part old engine grease was used following recommendations provided by the Elephant Pepper Development Trust at a workshop held in Zambia in August 2004 (L. Osborn, pers. comm., 2004). The chilli-grease was reapplied every day because it washed off in the rain. Sitati \& Walpole (2006) also found that 'continuous application of chilli grease, on at least a weekly basis [is necessary] because of rain washing it off.'

The chilli and sirens site also had a series of four watchtowers manned by 2-3 guards who actively chased elephants away from the fields and back into the Park. The chilli and sirens site had fewer towers than the conventional site because a road and houses formed its northern border and there were fewer elephant active routes in this site (Fig. 2). The difficulty in finding identical sites for compar- isons of human-elephant conflict mitigation methods is a well-known problem. The conventional and chilli and sirens sites were the best pair of sites known to us at the time of the trials.

During the October 2005 to April 2006 test period we hired local villagers to act as guards to ensure that we would be able to compare community-based crop-guarding schemes with and without chilli-based deterrents. In the previous 2 years of work around Way Kambas National Park we had attempted to initiate community-based crop guarding on a voluntary basis. That is, we had provided farmers with tools (e.g. sirens, spotlights and chillies) and helped them build watch-towers but we were unsuccessful in our attempts to encourage sufficiently intense guarding rotas (Gorog \& Gunaryadi, 2005). This sporadic participation by the farmers 


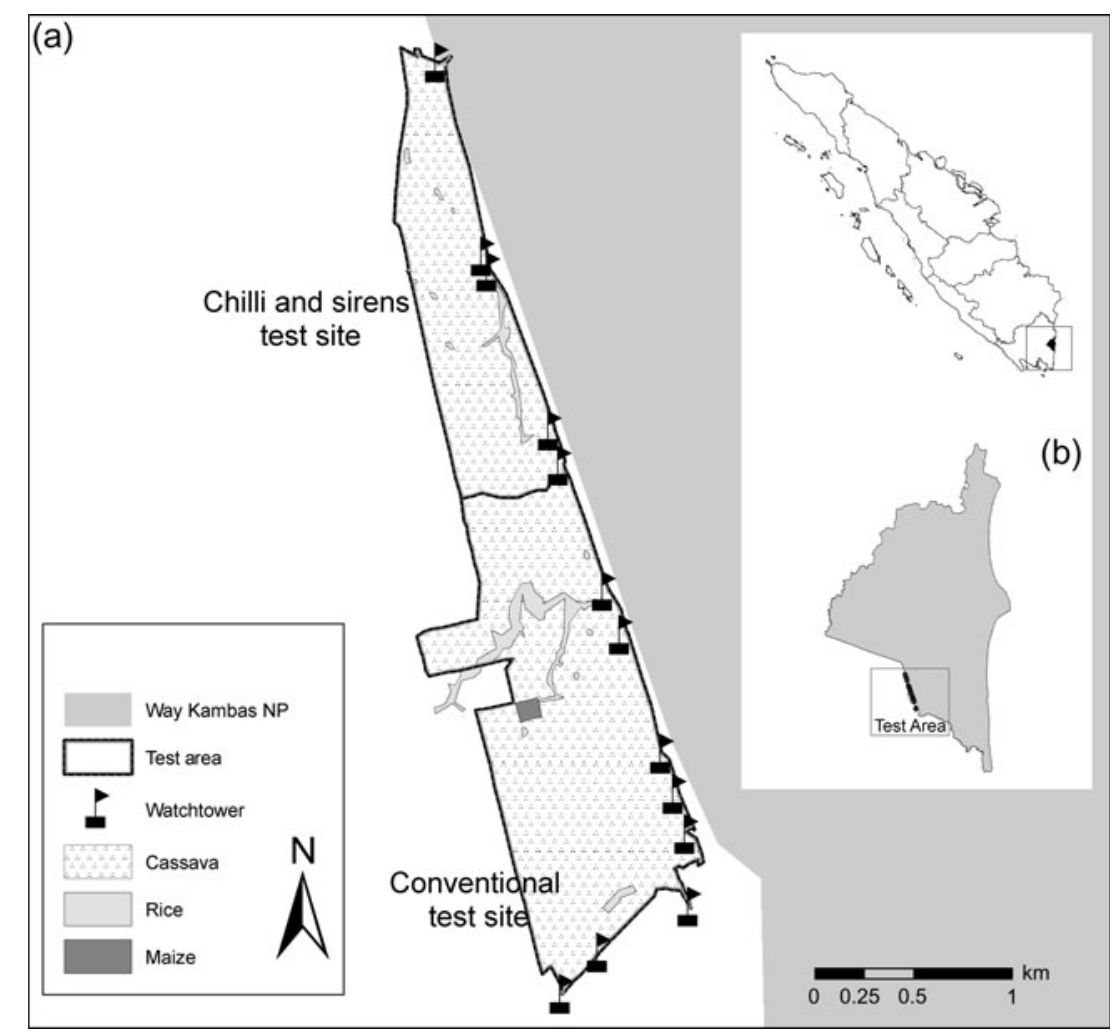

FIg. 2 (a) Location of the October 2005 to April 2006 trial sites adjacent to Way Kambas National Park (Fig. 1) showing the conventional and chilli and sirens test sites, the locations of the watch-towers, and the areas under different crops (see text for further details). The farmers' voluntary repeat trial in 2007 covered all the combined conventional site and the chilli and sirens site but only conventional methods were used. (b) The location of the test area depicted in (a) in Way Kambas National Park.

handicapped our attempts to evaluate chilli-based deterrents but is understandable because the farmers were often too tired to guard their crops at night because they had been working in their fields all day. Moreover, farmers around Way Kambas National Park had little faith in the efficacy of crop-guarding systems because of the poor success rates they had experienced in the past (authors, pers. obs.) and they were thus unenthusiastic about participating in our earlier voluntary trials.

To help encourage the adoption of sustainable (voluntary) human-elephant conflict reduction methods we initiated and fostered self-resilience groups (Kelompok Swadaya Masyarakat) in villages around Way Kambas National Park. This approach was intended to facilitate and promote self-help schemes, including the post-trial establishment of voluntary crop-guarding rotas.

\section{Chilli-based crop protection methods not used}

Prior to the trials we tested the use of chilli-dung fires along the agriculture-forest interface at Way Kambas National Park. We mixed ground dried chillies with fresh elephant or cow dung and then dried the mixture to make briquettes that could be burnt to produce a noxious smoke. A ratio of 1 $\mathrm{kg}$ dry ground chillies per $2 \mathrm{~kg}$ wet dung was used following recommendations provided by the Elephant Pepper Development Trust at a workshop held in Zambia in 2004 (L. Osborn, pers. comm., 2004). Unfortunately, the prevailing wind direction at Way Kambas National Park was such that the chilli-dung fires were of no use: the smoke produced drifted towards the crop fields and watch-towers rather than over the scrubby forest at the edge of the Park. However, field trials in the northern Congo region have suggested that burning chilli-dung can be effective at deterring elephants from entering crop fields (E. Stokes, pers. comm., 2007; see also Osborn \& Parker, 2002a).

\section{Crop damage assessment}

Our previously established Problem Animal Recorder teams collected data on human-elephant conflict around Way Kambas National Park from September 2005 to May 2006. The teams visited the villages around the Park about twice per month (sometimes more frequently depending on reported elephant-raiding frequency). In addition, we developed a network of local village informants who notified our teams when crop-raiding incidents occurred so as to facilitate rapid evaluation of incidents. Each crop damage incident was assessed to see whether it constituted an 
TABLE 1 Comparison of the effectiveness of two different crop protection systems (community-based crop guarding with conventional tools, at the conventional site, and community-based crop guarding with chilli-grease fences and tripwire-triggered sirens at an adjacent site, the chilli and sirens site), over a 140-night period from October 2005 to April 2006, and the effectiveness of voluntary communitybased crop guarding using conventional tools over a 116-night period during January-May 2007 at the two sites combined, with the characteristics of the two sites. In 2007 the number of towers was reduced from 12 to 10 because two of the original towers were deemed to be too far from the Way Kambas National Park border and the farmers decided they could guard their crops from another tower located closer to the border.

\begin{tabular}{|c|c|c|c|c|c|c|c|c|c|c|c|}
\hline Site & $\begin{array}{l}\text { No. of } \\
\text { towers }\end{array}$ & $\begin{array}{l}\text { Boundary } \\
\text { length } \\
(\mathrm{km})\end{array}$ & $\begin{array}{l}\text { Cassava } \\
\text { (ha) }\end{array}$ & $\begin{array}{l}\text { Rice } \\
\text { (ha) }\end{array}$ & $\begin{array}{l}\text { Maize } \\
\text { (ha) }\end{array}$ & $\begin{array}{l}\text { Watermelon } \\
\text { (ha) }\end{array}$ & $\begin{array}{l}\text { Tall grass } \\
\text { (ha) }\end{array}$ & $\begin{array}{l}\text { Others } \\
\text { (ha) }\end{array}$ & $\begin{array}{l}\text { No. of } \\
\text { guarding } \\
\text { nights }\end{array}$ & $\begin{array}{l}\text { No. of } \\
\text { attempted } \\
\text { raids }\end{array}$ & $\begin{array}{l}\text { No. of } \\
\text { successful } \\
\text { raids (\%) }\end{array}$ \\
\hline \multicolumn{12}{|l|}{$2005-2006$} \\
\hline Chilli \& sirens site & 4 & 2 & 90.6 & 3.0 & 0.0 & & & & 140 & 34 & $3(8.8)$ \\
\hline Conventional site & 8 & 2 & 173.5 & 7.5 & 1.1 & & & & 140 & 57 & $5(8.8)$ \\
\hline $\begin{array}{l}\text { Total } \\
2007\end{array}$ & 12 & 4 & 264.1 & 10.5 & 1.1 & & & & 280 & 91 & $8(8.8)$ \\
\hline Two sites combined & 10 & 4 & 237.1 & 20.6 & 0 & 12 & 0.75 & 5.35 & 112 & 178 & $22(12.4)$ \\
\hline
\end{tabular}

independent event, which we defined as a single foray occasion, i.e. when an elephant or group of elephants crossed the Park boundary, entered farmland and damaged crops (Naughton-Treves, 1998). The crop type damaged and the date and time of all incidents were noted, and the location of the incidents was recorded using a global positioning system.

\section{Assessing the effectiveness of the defences}

We monitored challenges to the defences by recording the proportion of elephant crop-raiding attempts (along the defended agriculture-elephant interface) that were repelled for the area that had chilli-grease fences (the chilli and sirens site) and the area that did not (the conventional site; cf. Sitati \& Walpole, 2006). Monitoring of challenges was conducted every night, from before dusk to after dawn, by the guards and our field technicians, with assistance from our Problem Animal Recorder teams as necessary.

While it would be interesting to know the reaction time of elephants to the various methods used in the study, it is not essential for an assessment of the differential effectiveness of the crop defence methods. What matters, in practical terms, is whether the elephants were repelled. Monitoring reaction times at night in a conflict situation involving dangerous animals is not easy, which was why it was not part of our protocol.

\section{Results}

From 22 October 2005 to 5 April 2006 there were 34 attempts by elephants to enter crop fields (challenges to the defences) at the chilli and sirens site, of which only three (8.8\%) were successful, and 57 attempts to enter crop fields at the conventional site, of which only five (8.8\%) were successful (Table 1). Over the same period there were 401 crop-raiding incidents elsewhere around Way Kambas
National Park. Thus, $91.2 \%$ of attempted raids were repelled at both sites and there was no difference in the effectiveness of the methods used at the conventional site and at the chilli and sirens site.

Following the success of these tests farmers in both the former chilli and sirens and conventional sites decided to voluntarily adopt the conventional crop defence methods for the period 17 January 2007 to 12 May 2007; they did not adopt the chilli and sirens method. No guards were paid by our project during this second voluntary trial but the tools used by the farmers were those we supplied in 2005-2006. During this 116-night period of voluntary guarding, $87.6 \%$ of attempted raids by elephants were successfully repelled (Table 1).

Furthermore, in this voluntary phase, we observed that the farmers' confidence had increased and they were prepared to plant more high-risk crops such as rice and watermelons (high risk because they are favoured by elephants). The area under rice increased by almost $100 \%$ (from 10.5 to 20.6 ha; Table 1).

\section{Discussion}

\section{Our results}

We found that community-based crop-guarding methods using conventional tools without any chilli-based deterrents were effective at keeping elephants out of crop fields in 91.2 and $87.6 \%$ of attempted raids in 2005-2006 and 2007, respectively. Furthermore, chilli-grease fences did not add any significant deterrent effect but did add expense and create additional work, and burning chilli-dung was impracticable. The most significant additional work requirement created using chilli-based deterrents was the need to reapply chilli-grease to the fences every day because it washed off in the rain (see also Sitati \& Walpole, 2006, and Graham \& Ochieng, 2008). 
Encouragingly, our trials, like those of Osborn \& Parker (2002a) and Sitati \& Walpole (2006), show that it is possible to keep elephants out of crop areas adjacent to elephant habitat using unsophisticated tools and guarding techniques and suggest that farmers will voluntarily adopt such methods if their effectiveness is demonstrated.

There were more attempts by elephants to enter fields at the conventional site, where there was a small amount of maize (1.1 ha) in addition to the cassava and rice found at the chilli and sirens site (Table 1 ). This small disparity in the available palatable resources could explain the difference in the number of attempted raids between the two sites (57 vs 34) but this is irrelevant: what is important is the proportion of attempted raids that were repelled by the defences, which is what our teams recorded. There is no requirement for the number of attempted raids per site to be the same.

\section{The chilli model}

Osborn, Parker, and others argue that chillies should not be expected to work in isolation (Osborn \& Parker, 2002b; Parker et al., 2007). Osborn \& Parker (2002b, 2003) further argue that both increased farmer vigilance and a range of deterrents are necessary to reduce the damage caused by elephants and that it is necessary to convince farmers that they can, and should, take responsibility for protecting their own crops: '[the] central theme that emerges from examination of the failures of intervention is the need to decentralize responsibility for crop protection to the farmers. This represents a considerable shift in thinking, because farmers have historically depended on centralized PAC [Problem Animal Control] units to reduce this conflict'. We agree with these arguments. We also recognize that the chilli-based approach to the mitigation of human-elephant conflict is multifaceted; i.e. chillies are a high-value crop that is unpalatable to elephants and thus little damaged during crop raids (Parker \& Osborn, 2006), chillies can be sold at fair trade prices, and growing chillies provides farmers with an opportunity to add value to their crops by making and selling elephant-friendly products such as chilli sauces (Parker et al., 2007). Nothing in our work in Sumatra suggests that these aspects of the chilli model are flawed (although we have concerns about market saturation and food security if large numbers of farmers adopt chillies as a major cash crop in areas susceptible to crop depredation). Another part of the chilli model is that some of the chilli crop can be used to produce deterrents (chilli-grease and chilli-dung) to help keep elephants out of crop fields or other areas (Osborn \& Parker, 2002a,b; WWF, 2005; Parker et al., 2007) and it is the value of this last part of the model that we question.

Following a review of the published and grey literature to see whether we could find evidence that chillies added significant deterrent effect in other trials, we concluded that there has been no clear demonstration that chillies are a necessary part of the deterrent toolkit. In all the work we reviewed chillies were used as part of a suite of deterrents and there was also a simultaneous emphasis on farmer vigilance. Our study is apparently the only attempt to assess the contribution of chilli-based deterrents to this suite of measures. Sitati \& Walpole (2006) is probably the most cited example of the value of chilli-based deterrents; however, the authors did not demonstrate a clear deterrent effect of chillies because they were used as part of a suite of deterrents and there was also a simultaneous emphasis on farmer vigilance. As with our chilli and sirens site, Sitati \& Walpole (2006) used a combination of chilli-grease fences plus farmers armed with torches who guarded fields and who responded to attempted raids by elephants. Therefore, because chillies were used as part of a suite of deterrents, it is unclear whether the chillies were a necessary component of the crop defences. Similar considerations apply to the work of Osborn \& Parker (2002a) and Graham \& Ochieng (2008). Sitati \& Walpole (2006) wrote, '[a] combination of early warning to detect elephants before they entered farms, coupled with a front line communal guarding strategy, proved most successful', which is what we conclude here based on our trials of crop defence systems in Sumatra.

Chilli extracts in aerosol form have proven effective (Osborn \& Rasmussen, 1995); such methods are, however, relatively high tech and expensive and thus not well suited to the community-based methods that are now widely recognized as necessary for sustainable management of human-elephant conflict (Parker et al., 2007).

\section{Villager participation}

An important factor in the 2005-2006 trials was the hiring of local villagers to act as guards. In the previous 2 years of work around Way Kambas National Park we had attempted to initiate community-based crop guarding on a voluntary basis, provided farmers with tools (e.g. sirens, spotlights and chillies) and helped build watch-towers but we were unsuccessful in our attempts to encourage sufficiently intense guarding rotas (see Graham \& Ochieng, 2008 , for similar observations). Because of this problem we hired villagers (not necessarily farmers) to act as guards in the 2005-2006 trials so that we could ensure the watchtowers were manned and thus effectively compare community-based crop-guarding schemes with and without chilli-based deterrents. We recognize that non-governmental organizations (or other organizations) paying guards is not sustainable and thus, once the farmers had seen that low-tech participatory methods were capable of successfully repelling the majority of attempted raids by elephants, we concentrated on promoting self-reliance and voluntary guarding. Following the encouraging voluntary adoption of the low-tech participatory crop-guarding methods at both 
our former test sites in 2007 the challenge now is to promote these methods at other sites.

\section{Conclusions and recommendations}

Chillies are unpalatable to elephants and thus a suitable crop for areas with high rates of crop depredation. Chillies can also be made into products such as elephant-friendly sauces, which can add value to farmers' harvests. However, our work calls into question the use of chilli products as elephant deterrents. Specifically, chilli-grease-covered fences contributed no deterrent effect to crop defence systems tested in Sumatra and burning chilli-dung was impracticable. In contrast, low-tech community-based crop-guarding methods using a combination of early warning systems, vigilance and active responses to drive elephants away were successful in repelling $91.2 \%$ of attempted raids in 20052006 and $87.6 \%$ of attempted raids in 2007. No other studies have attempted to identify what contribution, if any, chilli-based deterrents make to crop defence systems, so it is not possible to make a general conclusion about their utility. We suggest, therefore, that additional tests are needed to evaluate chilli-based deterrents better, under a variety of conditions, before these methods are further promoted (see also Hanks, 2006). Such tests should address issues of cost and practicality relative to other crop defence systems. For example, it is possible that chilli-based methods may provide some deterrent effect under certain conditions but still cost more than alternative methods and/or be more time-consuming to apply.

More generally, our work in Sumatra adds to the growing body of evidence that shows the key to successful reduction of human-elephant conflict is cooperative community-based crop-guarding systems involving early warning systems, vigilance and active responses to elephants (Osborn \& Parker, 2002a; Sitati \& Walpole, 2006; but see Graham \& Ochieng, 2008). These community-based methods thus warrant further testing to assess (1) the ease or otherwise of setting up such systems in different areas, (2) their effectiveness, and (3) the costs and benefits of these methods relative to alternative approaches to humanelephant conflict mitigation.

\section{Acknowledgements}

Our research was a collaborative effort by the Wildlife Conservation Society's Indonesia Program and the Indonesian Ministry of Forestry's Directorate General of Forest Protection and Nature Conservation. The work was funded by the Wildlife Conservation Society and the US Fish \& Wildlife Service (through the Asian Elephant Conservation Fund, Grant Number 98210-5-G175). We are grateful to all these organizations. We thank J. Ginsberg, C. Poole, P. Clyne, N. Andayani, N. Brickle, A. Gorog and M. Nagendran for their support and advice during the project. The work would not have been possible without the dedication of our field teams. We are particularly grateful to Sukatmoko, Sugiyo, J. Sidabalok, D. Ariesta and A. Yanuar for their dedication and patience in dealing with farmers. We would also like to acknowledge our other colleagues from WATALA, the head of Way Kambas National Park and his staff and the Way Kambas Conservation Network. We would like to thank Rosie Woodroffe, Matt Walpole and Richard Hoare for their helpful comments on an earlier version of this paper and Loki Osborn and Guy Parker for numerous helpful discussions.

\section{References}

BARNES, R.F.W. (1996) The conflict between humans and elephants in the central African forests. Mammal Review, 26, 67-80.

Dyah Juliana, S., Oen, L.H., Azizahwati \& Winarno, F.G. (1997) Capsaicin content of various varieties of Indonesian chillies. Asia Pacific Journal of Clinical Nutrition, 6, 99-101.

Foose, T.J. \& van Strien, N. (1997) Asian Rhinos-Status Survey and Conservation Action Plan. IUCN, Gland, Switzerland, and Cambridge, UK.

Franklin, N., Bastoni, Sriyanto, Siswomartono, D., MANANSANG, J. \& Tilson, R. (1999) Last of the Indonesian tigers: a cause for optimism. In Riding the Tiger: Tiger Conservation in Human-Dominated Landscapes (eds J. Seidensticker, S. Christie \& P. Jackson), pp. 130-147. Cambridge University Press, Cambridge, UK.

Gorog, A. \& Gunaryadi, D. (2005) Protecting Sumatran Elephant Populations and Resolving Human-Elephant Conflicts in Way Kambas National Park, Sumatra, Indonesia. Interim Report to the USFWS/AsECF, March 2005. Unpublished Report. Indonesia Program, Wildlife Conservation Society, Bogor, Indonesia.

Graham, M.D. \& Ochieng, T. (2008) Uptake and performance of farm-based measures for reducing crop raiding by elephants Loxodonta africana among smallholder farms in Laikipia District, Kenya. Oryx, 42, 76-82.

Hanks, J. (2006) Mitigation of Human-Elephant Conflict in the Kavango-Zambezi Transfrontier Conservation Area Through Community Based Problem Animal Control, With Particular Reference to the Use of Chilli Peppers. Final Report. December 2006. Conservation International, Washington, DC, USA.

Hedges, S., Tyson, M.J., Sitompul, A.F. \& Hammatt, H. (2006) Why inter-country loans will not help Sumatra's elephants. Zoo Biology, 25, 235-246.

Hedges, S., Tyson, M.J., Sitompul, A.F., Kinnaird, M.F., Gunaryadi, D. \& Aslan (2005) Distribution, status, and conservation needs of Asian elephants (Elephas maximus) in Lampung Province, Sumatra, Indonesia. Biological Conservation, $124,35-48$.

HoARe, R. (1995) Options for the control of elephants in conflict with people. Pachyderm, 19, 54-63.

HoAre, R.E. (2000) African elephants and humans in conflict: the outlook for co-existence. Oryx, 34, 34-38.

KANGWANA, K.F. (1995) Human-elephant conflict: the challenge ahead. Pachyderm, 19, 11-14.

Kemf, E. \& Santiapillai, C. (2000) Asian Elephants in the Wild, 2000. A WWF Species Status Report. WWF-International, Gland, Switzerland.

Loudon, B. (2007) Chilli to truncate elephant binging. The Australian, 16 November 2007. 
Naughton, L., Rose, R. \& Treves, A. (1999) The Social Dimensions of Human-Elephant Conflict in Africa: A Literature Review and Case Studies From Uganda and Cameroon. A Report to the IUCN/SSC African Elephant Specialist Group's Human-Elephant Conflict Task Force. Unpublished Report. IUCN, Gland, Switzerland.

Naughton-Treves, L. (1998) Predicting patterns of crop damage by wildlife around Kibale National Park, Uganda. Conservation Biology, 12, 156-168.

Nyhus, P.J., Tilson, R. \& Sumianto (2000) Crop raiding elephants and conservation implications at Way Kambas National Park, Sumatra, Indonesia. Oryx, 34, 262-274.

Oldeman, L.R., Las, I. \& Darwis, S.N. (1979) An agroclimatic map of Sumatra. Contributions of the Central Research Institute for Agriculture Bogor, 52, 1-35.

Osborn, F.V. (2002) Capsicum oleoresin as an elephant repellent: field trials in the communal lands of Zimbabwe. Journal of Wildlife Management, 66, 674-677.

Osborn, F.V. \& Parker, G.E. (2002a) Community-based methods to reduce crop loss to elephants: experiments in the community lands of Zimbabwe. Pachyderm, 33, 32-38.

Osborn, F.V. \& Parker, G.E. (2002b) Living With Elephants II: A Manual. Mid Zambezi Elephant Project, Harare, Zimbabwe.

Osborn, F.V. \& Parker, G.E. (2003) Towards an integrated approach for reducing the conflict between elephants and people: a review of current research. Oryx, 37, 80-84.

Osborn, F.V. \& Rasmussen, L.E.L. (1995) Evidence for the effectiveness of an oleo-resin capsicum aerosol as a repellent against wild elephants in Zimbabwe. Pachyderm, 20, 55-64.

PARKER, G.E. \& OSBorn, F.V. (2006) Investigating the potential for chilli Capsicum annuum to reduce human-wildlife conflict in Zimbabwe. Oryx, 40, 1-4.

Parker, G.E., Osborn, F.V., Hoare, R.E. \& NisKanen, L.S. (eds) (2007) Human-Elephant Conflict Mitigation: A Training Course for Community-Based Approaches in Africa. Participant's Manual. Elephant Pepper Development Trust, Livingstone, Zambia, and IUCN/SSC AfESG, Nairobi, Kenya.
Reilly, J. (2002) The biology, ecology and conservation of the Sumatran elephant Elephas maximus sumatranus in Way Kambas National Park, Sumatra. PhD thesis, Manchester Metropolitan University, Manchester, UK.

Santiapillai, C. \& Jackson, P. (1990) The Asian Elephant: An Action Plan for Its Conservation. IUCN/SSC Asian Elephant Specialist Group, Gland, Switzerland.

Sitati, N.W. \& Walpole, M.J. (2006) Assessing farm-based measures for mitigating human-elephant conflict in Transmara District, Kenya. Oryx, 40, 279-286.

Siтом P UL, A.F. (2004) Conservation implications of human-elephant interactions in two national parks in Sumatra. MSc thesis, University of Georgia, Athens, USA.

UNDP/FAO (1979) Way Kambas Management Plan 1980-1985. Unpublished Report. UNDP/FAO National Park Development Project INS/78/061. FAO, Bogor, Indonesia.

Upadhye, A.S. (2007) Great Indian rope to do the trick. The Times of India, 19 November 2007.

WWF (World Wide Fund For Nature) (2005) Human Wildife Conflict Manual. Wildlife Management Series. WWF, Southern African Regional Programme Office (SARPO), Harare, Zimbabwe.

\section{Biographical sketches}

SimON HedGes' research interests include human-wildlife conflict mitigation and evidence-based approaches to conservation. He has worked on human-elephant conflict in several countries in South-east Asia, coordinates the Asian Elephant Conservation Program of the Wildlife Conservation Society and is the co-chair of the IUCN/Species Survival Commission's Asian Elephant Specialist Group. Donny GUNARYADi has worked on Asian elephant conservation projects for the Wildlife Conservation Society since 2000. He has previously been involved in field research projects on ungulates in East Java, birds in West Java and coral reef monitoring work in Semak Daun Island in Kepulauan Seribu Marine National Park. 